\title{
OPTIMUM DESIGN OF CROWN BRAKES USING REAL-CODED GENETIC ALGORITHMS
}

\author{
Hesham A. Hegazi \\ Assistant Professor, Department of Mechanical Engineering, \\ The American University in Cairo (AUC), Cairo 11511, EGYPT \\ Email: hhegazi@aucegypt.edu
}

(Received January 26, 2008 Accepted March 8, 2008)

This paper presents an optimum design procedure of crown brakes. Crown brake differs from drum brake as it has heat input from both inner and outer surfaces. It also differs from disc brakes as it is equivalent to a disc brake with larger diameter, and the friction surfaces are curved into a cylindrical shape. This can improve the performance of previous commonly used brakes. On the other hand, this is the main cause of high thermal loads on the brake rotor. These loads can produce surface damage and rotor failure due to excessive surface temperature and thermal fatigue. Optimum design procedure is carried out in order to find out the optimum design variables. Multi-objective optimization is used which combines the minimization of the brake weight, and temperature due to braking. Constraints to the optimization problem are the geometrical constraints and the maximum thermal compressive stress. Design variables are taken to be the rotor diameter and thickness, rotor width, and pad arc of contact length. Optimum design results are presented graphically for a wide range of energies and deceleration rates.

KEYWORDS: Friction brakes, Crown brakes, Optimum design, Genetic Algorithms, Multi-objective optimization.

\section{INTRODUCTION}

Many efforts have been done to improve the braking system performance and meet the ever increasing speed and power requirements. The introduction of the disc brake represents one of these efforts. Disc brakes are considered to be better than the commonly used drum brakes, while crown brakes are considered the best compared to disc and drum brakes. The crown brake is equivalent to a disc brake with a larger diameter, and where the friction surfaces have been curved into a cylindrical shape [10]. A comparison of both types showing the diameter increases due to the use of a crown brake is shown in Figure (1).

The crown brake consists of a rotor of cylindrical section and having a thickness slightly smaller than that of a disc brake. The use of crown brakes has been suggested as a means of improving the performance of frictional brakes. A crown brake, which differs from disc or drum brake systems, has heat input from both the inner and outer surfaces. The crown brake can be viewed as a cross brake, with a drum rotor and a disc caliper, combines the advantages of both drum and disc. It has the loading symmetry of the disc caliper which results in less mechanical deformations. It 
also has the larger friction surface areas and heat exchange areas of the drum which result in better thermal performance and lower temperatures [4].

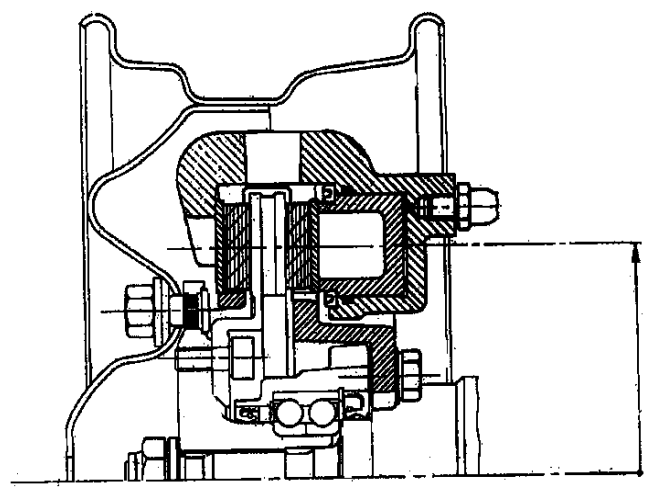

a) Ventilated disc brake

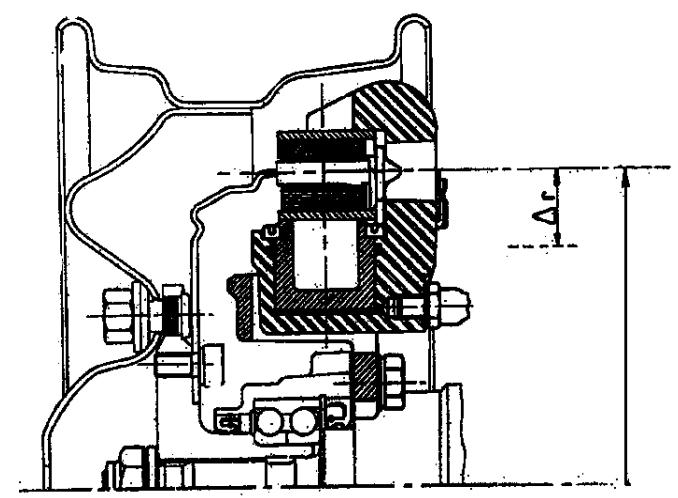

b) Crown brake

Figure 1: Comparison between Disc and Crown bakes [10]

Due to the wide application of frictional brakes, many researchers investigated the effect of pressure distribution as well as temperature distribution in both disc and drum brakes using several techniques [1, 2, 12 to 16]. Newcomp et al., [10 to13], derived expressions for the calculations of the temperature rise in drum, and disc brakes. Triovic, et al., [17], studied the disc brake interface pressure distributions, and its effect on the performance of the brake in terms of torque, temperature distribution, and wear.

Using the closed form approximate equations defining the brake performance, many researchers stared optimizing the performance of different types of brakes. Dike [3], described the conduction of heat in breaking disc and has been a base for optimum design of braking discs based on temperature as the limiting factor. The design variables to optimize are, the outer radius, and the property of disc material. Metwalli, et al., [8], proposed a multi-objective optimization procedure for disc brakes. The two objectives chosen are to minimize the temperature and the disc volume. The proposed method showed an improvement in the optimum design marked by the superiority in the optimum design values compared with previous researchers.

Mouza, [10], described in his paper the construction and thermal performance of crown brakes. In order to demonstrate the performance of crown brakes, a comparison between disc brakes is conducted. Under standard tests for testing automotive brakes, better results is obtained using crown brakes while maintaining same operating conditions. Drum brakes showed the lower surface temperature during braking followed by crown brakes. Disc brakes pretended the highest temperature in continuous braking and Alpine test. The author concluded with the superiority of the crown brakes over disc brakes, especially from the point of view of economic advantages.

Elbella, A., et al., [4], suggested an algorithm for the design of the optimal thermal load sharing and configuration of the rotor for crown brakes of different ratios of inner to outer radius. The algorithm is a simplified one-dimensional finite difference analysis. Using this analysis, the interfacial temperature and thermal stresses (radial 
and tangential) are calculated. Optimum design was carried out in order to determine the ratio that will produce the best thermoelastic performance. The design objective was the maximum temperature, maximum tensile tangential stress, maximum compressive stress, and difference between the maximum tensile and compressive tangential stresses. An extension of the previous objective function taking into consideration the effect of rotor shape (or profile) along with the load sharing ratio was conducted for the overall rotor performance. A 50\% weight reduction was obtained without any loss in the performance when optimizing both the load sharing and rotor profile.

In this paper, Genetic Algorithms (GAs) are used to solve the problem of optimizing crown brakes. GAs are search algorithms based on the mechanics of natural selection and natural genetics. They combine survival of the fittest among string structures with a structured yet randomized information exchange to form a search algorithm with some of innovative flair of human search. In every generation, a new set of artificial creatures (strings) is created using bits and pieces of the fitted of the old; an occasional new part is tried for good measure. While randomized, GAs are no simple random walk. They efficiently exploit historical information to speculate on new search points with expected improved performance.

\section{THEORETICAL BACKGROUND}

This section deals with the equations governing the design and performance of crown brakes. Figure (2) shows the configuration of a crown brake.

In calculating the braking torque we assume that the rotor is sufficiently rigid to give uniform wear over the lining and that the wear is proportional to the product of velocity and pressure.

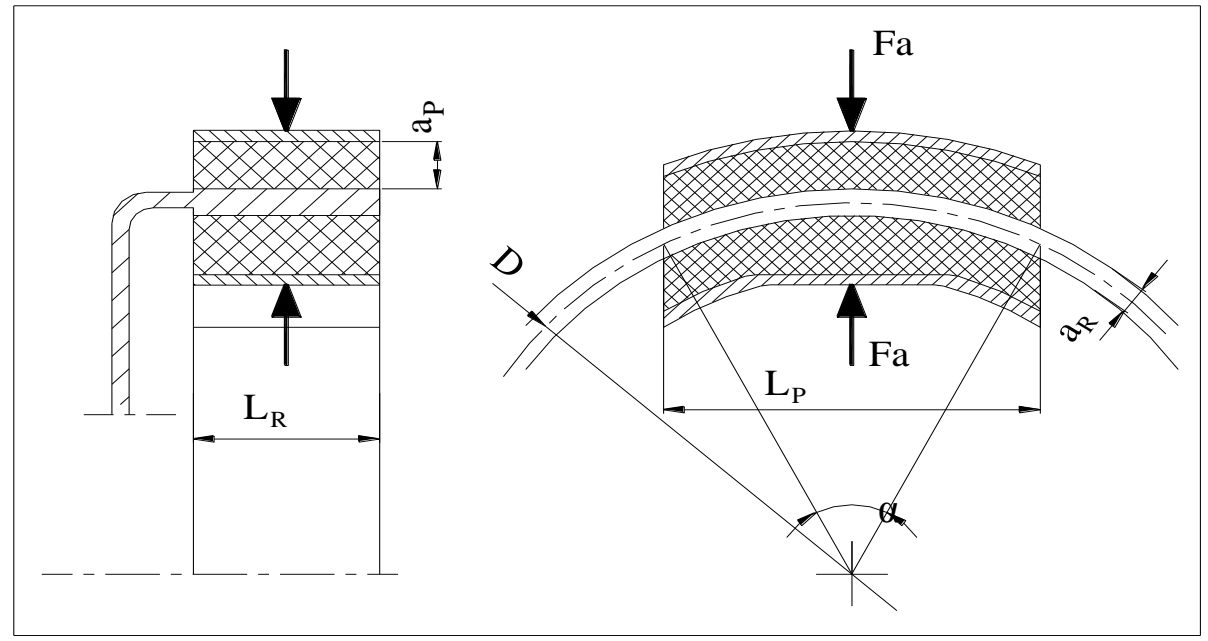

Figure 2: Configuration of a crown brake

The total normal force $\left(F_{a}\right)$, is found in terms of rotor diameters $(D)$, and for a certain range of $\alpha$ instead of a full rotor, one gets

$$
\mathrm{F}_{\mathrm{a}}=\frac{\alpha}{2} \mathrm{p}_{\max } D L_{R}
$$


The torque is found by multiplying the force on the element by the coefficient of friction $(\mu)$ and the area. The torque is then given by

$$
\mathrm{T}=\mu F_{a}(D / 2)=\frac{\alpha}{4} \mu p_{\max } D^{2} L_{R}
$$

During braking, heat is generated by friction at the interface of the contauuny bodies and is then transferred by conduction into each body. Newcomb [17] gives the proportion of total heat generated that is transmitted to the rotor by the following relation.

$$
\lambda=\frac{1}{1+\frac{A_{2}}{A_{1}} \sqrt{\frac{\rho_{2} c_{2} k_{2}}{\rho_{1} c_{1} k_{1}}}}
$$

In case of a crown brake where one area of the pad's material slides against each face of the rotating rotor, one can take $\left(A_{2} / A_{1}\right)=\alpha / 360$. The proportion of total heat generated is then given by:

$$
\lambda=\frac{1}{1+\frac{\alpha}{360} \sqrt{\frac{\rho_{2} c_{2} k_{2}}{\rho_{1} c_{1} k_{1}}}}
$$

The surface temperature of the rotor and the lining must not exceed a certain permissible value for rotor material otherwise it influences the wear of the lining material and friction coefficient (fade). Other effects of high brake surface temperatures are the thermal distortion of the rotor or surface cracking as a result of plastic deformation from high thermal stresses.

The following equations determine the rotor surface temperature due to braking. Newcomb et al., [12 to 15], derived the following equations for determining the temperature rise at the interface of rotor and lining at any instant of time $(t)$ during a brake application of duration $\left(t_{s}\right)$. They have used the assumptions that there is no heat loss to the atmosphere (suitable for short values of brake application time). The rotor can be considered of infinite thickness under the assumptions that the heat loss to the atmosphere is very small (compared to the total heat generated) and can be neglected. The problem is considered a semi infinite conduction heat transfer. The equations for surface temperature depend on the time as follows.

For $0<\mathrm{t}<2$, the surface temperature can be obtained from

$$
\theta=\frac{2 \mathrm{Q}_{1}}{\mathrm{t}_{\mathrm{s}}{ }_{1}} \sqrt{\frac{\alpha_{1} \mathrm{t}}{\pi}}\left(1-\frac{2 \mathrm{t}}{3 \mathrm{t}_{\mathrm{s}}}\right)
$$

For $2<\mathrm{t}<\mathrm{t}_{\mathrm{s}}$, the surface temperature can be obtained from

$$
\theta=\frac{2 \alpha_{1} \mathrm{Q}_{1}}{\mathrm{t} \mathrm{k}_{\mathrm{s} 1} \mathrm{a}_{\mathrm{R}}}\left\{\mathrm{t}\left(1-\frac{\mathrm{t}}{\mathrm{t}}\right)+\frac{\mathrm{a}_{\mathrm{s}}^{2}}{12 \alpha_{1}}\left(1-\frac{\mathrm{t}}{\mathrm{t}}\right)+\frac{a_{\mathrm{s}}^{4}}{720 \alpha^{2}{ }_{s}}\right\}
$$


where $Q_{1}$ is the thermal equivalent of heat per unit area entering the rotor $\left(\mathrm{J} / \mathrm{m}^{2}\right), \alpha_{1}$ is the thermal diffusivity of rotor material $\left(\mathrm{m}^{2} / \mathrm{s}\right), k_{l}$ is the thermal conductivity of rotor material $\left(\mathrm{W} / \mathrm{m}^{\circ} \mathrm{K}\right), a_{R}$ is the rotor thickness $(\mathrm{mm}), t$ is the time $(\mathrm{sec})$, and $t_{s}$ is the total braking time (sec).

Newcomb [12], showed that the thermal compressive stress at the rubbing path is given by the following two equations.

When $(\mathrm{t})$ is approximately less than $1.5 \mathrm{sec}$, one has

$$
\sigma=\frac{\sqrt{\alpha_{1}}}{k_{1}} \sigma_{0}\left[2 \sqrt{\frac{t}{\pi}}\left(1-\frac{2 t}{3 t_{s}}\right)-\frac{2 t \sqrt{\alpha_{1}}}{a_{R}}\left(1-\frac{t}{2 t_{s}}\right)\right]
$$

where $\alpha_{1}$ is the thermal diffusivity of rotor material $\left(\mathrm{m}^{2} / \mathrm{s}\right), k_{l}$ is the thermal conductivity of rotor material $\left(\mathrm{W} / \mathrm{m}^{\circ} \mathrm{K}\right), a_{R}$ is the rotor thickness $(\mathrm{mm}), t$ is the time $(\mathrm{sec})$, and $t_{s}$ is the total braking time ( $\left.\mathrm{sec}\right)$.

When $\mathrm{t}>1.5 \mathrm{sec}$, one have

$$
\sigma=2 \frac{\alpha_{1} \sigma_{o}}{a_{R} k_{1}}\left[\frac{a_{R}^{2}}{12 \alpha_{1}}\left(1-\frac{t}{t_{s}}\right)+\frac{a_{R}^{4}}{720 \alpha_{1}^{2} t_{s}}\right]
$$

with

$$
\sigma_{o}=\frac{Q_{1} Y \delta}{t_{S}(1-\gamma)}
$$

where $Q_{1}$ is the thermal equivalent of heat per unit area entering the rotor $\left(\mathrm{J} / \mathrm{m}^{2}\right), Y$ is the modulus of elasticity of rotor material (MPa), $\gamma$ is the Poisson's ratio of the rotor material, and $\delta$ is the coefficient of linear expansion of the rotor material $\left(/^{\circ} \mathrm{c}\right)$.

By considering the rotor of infinite thickness, the compressive stress at the rotor surface reduces to $[12,13]$

$$
\sigma=\frac{2 Y \delta}{k_{1}(1-\gamma)} E_{1}\left(\frac{\alpha_{1} t}{\pi}\right)^{1 / 2}\left(1-\frac{2}{3} \frac{t}{t_{s}}\right)
$$

which has a maximum value at $t=t_{s} / 2$ of

$$
\sigma_{\max }=\sqrt{\frac{8}{9 \pi}}\left(\frac{Y \delta E_{1}}{k_{1} t_{s}(1-\gamma)}\right) \sqrt{\alpha_{1} t_{s}}
$$

If the surface stress determined from the above equation exceeds the compressive strength of the material, surface rupture is possible [14].

The wear of brake materials when pressed against a steel or cast iron rotating surface is a complex of adhesive and oxidative wear and surface fatigue [12]. The wear model of the pads can be calculated by the equation [6]:

$$
w=W_{R} \frac{E}{2 A_{P}}
$$


where $w$ is the pad wear $(\mathrm{mm}), W_{R}$ is the wear rate of pad material $\left(\mathrm{mm}^{3} / \mathrm{J}\right), E$ is the total energy $(\mathrm{J}), A_{P}$ is the pad area $\left(\mathrm{mm}^{2}\right)$. The minimum pad thickness can be calculated as [8]:

$$
a_{P}=w^{*} Z
$$

Where the number of applications $(Z)$ that the brake is designed for can be calculated by the following equation [13]:

$$
Z=N * L_{b}
$$

where $N$ is the number of braking applications per hour $(1 / \mathrm{hr})$ and $L_{b}$ is the lining life for brakes (hr).

\section{REAL-CODED GENETIC ALGORITMS}

Genetic algorithms (GAs) have been used extensively to solve global optimization problems. Due to their promising performance, they have been used in optimization problems, along with other random-based global optimization techniques such as simulated annealing. The main body of a genetic algorithm is rather simple as exemplified by the following pseudo-code:

1. Let $F\left(X_{1}, \ldots, X_{m}\right)$ be an objective function to be optimized, where $\left(X_{1}, \ldots, X_{m}\right)$ are the independent variables, where each variable $\mathrm{Xi}$ ranges between a lower and an upper limit $\left[\mathrm{v}_{\min }, \mathrm{v}_{\max }\right] \mathrm{i}$.

2. Convert the function $\mathrm{F}$ from a minimization to a maximization problem, where a new function $\mathrm{f}(\mathrm{F})$ is to be maximized. The new function is known as the fitness function.

3. Generate a random population $P$ of $\mathrm{N}$ instances of the independent variables (known as agents).

4. For a pre-specified number of generations (iterations)

a. Let the total number of offspring agents due to the application of the mutation and cross over operators be denoted by $\mathrm{M}$.

b. Use the selection operator to fill a new population with N-M high fitness agents

c. Use the selection operator along with the mutation and cross over operators to fill the remaining M locations in the population

d. For the new population, evaluate the utility function (and fitness) value for the agents changed by cross over and mutation, and retain the fitness values of the unchanged agents. Steps (a) to (d) are demonstrated by Figure (3), where the darker rectangles denote the higher fitness agents.

5. End 


\section{Population}

\section{Intermediate}

population

Population

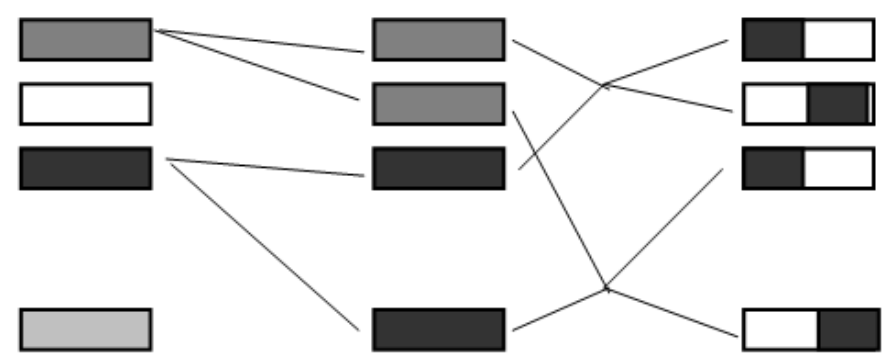

Selection

Cross-over \&

mutation

Figure 3: Generation of new populations in Genetic Algorithms

\subsection{Real-Coded vs. Binary Coded Genetic Algorithms}

Real coded genetic algorithms [7], use the real values of each agent instead of converting them into binary strings. The binary string representation was introduced in the early works of genetic algorithms, where each agent is mapped into a binary value. An example of such representation is shown in Figure (4a), for an arbitrary independent variable ranging from 0 to 31 . Assume that each digit in a location $i$ is multiplied by the factor $2^{\mathrm{i}}$ (i starts from the left with a value of zero), then a 5-digit binary string can represent the range of integer values 0 to 31 inclusive. The main reason for using such representation is that binary strings yield themselves to the genetic operators easily. In the early days of genetic algorithms research these operators were mere mimics of the biological operators. For example, the cross-over operator meant swapping the right-hand side binary digits of two agents, at the crossover point Figure (4b).

Binary coded genetic algorithms were shown to have two main drawbacks when dealing with continuous parameter optimization. The first drawback is that an independent variable with a large range of possible values would need a very long string to achieve decimal accuracy. This leads to an unnecessary enlargement of the search space. The second drawback is that binary coding may lead to a search space with Hamming cliffs. These are cliffs happen when the binary coding of two adjacent values differ in each one of their bits, and when their fitness values are different. For the example in Figure (4), the string 01111 represents 31 and the string 10000 represents 32. Assume that the global optimum is associated with the string 10000, and that the average fitness of the strings starting with 0 is higher than those starting with 1 . The genetic algorithms will most probably settle for the best solution within the vector space of strings starting with 0 , missing the global optimum [6]. 


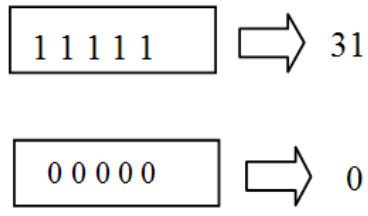

(a)

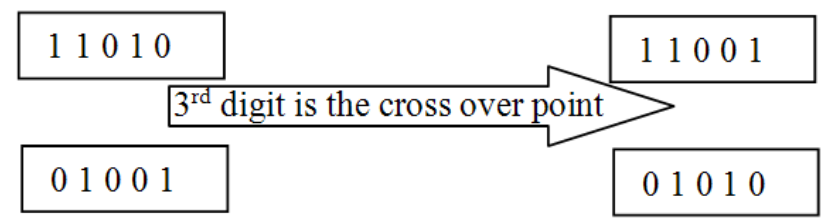

(b)

Figure 4: Binary coding of independent variables

In addition to being immune to the above-mentioned disadvantages, real-coded genetic algorithms have some advantages. First, real parameters make it possible to use large domains for the independent variables. Second, real parameters tend to exploit the gradual changes in the objective function corresponding to gradual changes in the independent variables. The above reasons led to the choice of real-coded genetic algorithms to seek the globally optimum shape of the C-frame cross-section. In the following sections the genetic operators that were programmed within the real coded genetic algorithm are described.

The selection scheme adopted is an elitist binary tournament selection, where the best agent is retained between successive generations, to ensure that there is no loss of the best-obtained agent. The tournament selection is modified to accommodate the selection of low fitness agents as well as high fitness agents. This modification is necessary as some mutation operators operate on low fitness agents.

Two cross over operators were used. These are: (1) Simulated binary cross over, and (2) Simple cross over.

\section{Simulated Binary Cross Over}

1. Select two agents with high fitness $A^{k}$ and $A^{j}, j,\{1, \ldots, N\} \& k,\{1, \ldots, N\}$.

2. Generate a random value $\mathrm{u},[0,1]$ from a uniform value. Use this value as an ordinate of the polynomial cumulative probability distribution (Deb, 1997), and obtain its corresponding abscissa value $\exists$.

3. Generate the offspring agents $B^{j}$ and $B^{k}$,

$$
\begin{aligned}
& \left.\mathrm{B}_{\mathrm{i}}^{\mathrm{j}}=0.5(1+\beta) \mathrm{A}_{\mathrm{i}}^{\mathrm{j}}+(1-\beta) \mathrm{A}_{\mathrm{i}}^{\mathrm{k}}\right] \\
& \left.\mathrm{B}_{\mathrm{i}}^{\mathrm{k}}=0.5(1-\beta) \mathrm{A}_{\mathrm{i}}^{\mathrm{j}}+(1+\beta) \mathrm{A}_{\mathrm{i}}^{\mathrm{k}}\right]
\end{aligned}
$$

where $\mathrm{i}$ refers to the $\mathrm{i}^{\text {th }}$ independent variable within the agent. This operator is presented as bias free cross over operator where the offspring agents are not biased towards any of the parent agents. 


\section{Simple Cross Over}

1. Select two agents with high fitness $A^{k}$ and $A^{j}, j,\{1, \ldots, N\} \& k,\{1, \ldots, N\}$.

2. Select a random discrete number $\mathrm{i},\{1, \ldots, \mathrm{m}\}$. Swap all values of the independent variables lying after the index $i$ between the $\mathrm{k}^{\text {th }}$ and $\mathrm{j}^{\text {th }}$ agents.

Three mutation operators were used in the search process. These are: (1) Beta mutation, (2) Boundary mutation, and (3) Uniform mutation.

\section{Beta Mutation}

1. Select an agent $A_{j}, j,\{1, \ldots, N\}$, with a high fitness value to be mutated.

2. For each independent variable $X_{i}$ within the agent, generate a value $v_{i}$, $\left[\mathrm{v}_{\min }, \mathrm{v}_{\max }\right], \mathrm{i},\{1, \ldots, \mathrm{m}\}$, from a beta distribution over the interval $\left[\mathrm{v}_{\min }, \mathrm{v}_{\max }\right]$ and whose peak is located at the non-mutated value for $\mathrm{X}_{\mathrm{i}}$.

The operator serves as a constrained random search probe in the vicinity of high fitness agents. The Beta distribution is used to assure that the generated values of the independent variables will not fall outside their pre-specified range.

\section{Boundary Mutation}

1. Select an agent $A_{j}, j,\{1, \ldots, N\}$, with a low fitness value to be mutated.

2. For each independent variable $X_{i}, i,\{1, \ldots, m\}$, within the agent, generate a value $\mathrm{v}_{\mathrm{i}}=$ either $\mathrm{v}_{\min }$ or $\mathrm{v}_{\max }$, at random.

The operator serves as a search probe at the extreme values of the independent variables, which is useful when the optimum value of the independent variables lie at the boundary of the search space.

\section{Uniform Mutation}

1. Select an agent $A_{j}, j,\{1, \ldots, N\}$, with a low fitness value to be mutated.

2. For each independent variable $X_{i}$ within the agent, generate a value $v_{i}$, $\left[\mathrm{v}_{\min }, \mathrm{v}_{\max }\right], \mathrm{i},\{1, \ldots, \mathrm{m}\}$, from a uniform distribution over the interval $\left[\mathrm{v}_{\min }, \mathrm{v}_{\max }\right]$. local optima.

It was shown that the operator is useful as a random search probe away from

The performance of genetic algorithms was previously analyzed using the socalled schema theorem [7]. In binary-coded genetic algorithms, a schema is a representation of a vector space, whose digits are partially specified and the rest can acquire any value. Considering the example in Figure (4), the schema $* * * * 1$ (where * stands for either 0 or 1 ), represents the set of all possible values greater than 15 . Genetic algorithms tend to accumulate agents belonging to schemata with high average fitness with a near exponential rate. The same concept was extended to the real-coded genetic algorithms, while another analysis showed that the number of generations $\gamma$ needed for agents with above average fitness to dominate the population is equal to:

$$
\gamma=\log _{2} \log _{2} \mathrm{~N}
$$

Where $\mathrm{N}$ is the population size. 


\section{PROBLEM FORMULATION AND RESULTS}

Frequently in complex design problems there are several quantities that can be considered design objectives. Therefore, a solution is sought that minimizes more than one objective since a single objective function does not specify all the desired goals. If for a given design problem, the minimization of one objective results in an increase in another objective, these objectives are said to be competing. This is the case in optimization of brake design where several objectives are competing. Objectives are the maximum design torque, and the minimum temperature and disc volume. The design vector is taken to be the rotor diameter $(D)$, the rotor width $\left(L_{R}\right)$, the pad angle $\left(\alpha_{P}\right)$, and the rotor thickness $\left(a_{R}\right)$.

$$
X=\left(D, L_{R}, \alpha_{P}, a_{R}\right)
$$

The optimization problem in the second objective can be stated as to find

$$
\text { min. } F=\theta^{4} \times V_{R}{ }^{B}
$$

where $\theta$ is the temperature and $V_{R}$ is the rotor volume, with the two $A$ and $B$ exponents to be optimized.

The objective function can then be written as follows:

When $0<\mathrm{t}<2$, we have

$$
F=\left\{\frac{2 \sqrt{\alpha_{1} t} Q_{1}}{t_{s} k_{1} \sqrt{\pi}}\left(1-\frac{2 t}{3 t_{s}}\right)\right\}^{A} \times\left\{\frac{\pi}{4} D^{2} L_{D} a_{R}\right\}^{B}
$$

Else for $2<\mathrm{t}<\mathrm{t}_{\mathrm{s}}$, we have

$$
F=\left\{2 \frac{\alpha_{1} Q_{1}}{t_{S} k_{1} a_{R}}\left\{t\left(1-\frac{t}{2 t_{s}}\right)+\frac{a_{R}{ }^{2}}{12 \alpha_{1}}\left(1-\frac{t}{t_{s}}\right)+\frac{a_{R}{ }^{4}}{720 \alpha_{1}^{2} t_{s}}-\right\}\right\}^{A} \times\left\{\frac{\pi}{4} D^{2} L_{D} a_{R}\right\}^{B}
$$

The constraints used in our optimization problem are:

- The maximum temperature attained during a single braking must be less than the maximum working temperature of the rotor material.

- The maximum thermal compressive stress must be less than the allowable compressive strength of the rotor material.

In the optimization program a minimum and a maximum limit of rotor diameter can be introduced for the iteration of the optimum outside diameter of the rotor. Free optimum rotor thickness and optimum outer diameter are achieved. The optimum dimensions and all required behavioral parameters are calculated.

The sample implementation used here is the same as the problem presented by Dike [3], with the following data:

- Total Weight of the car $(\mathrm{N})$

- Coefficient of friction between tire and road

- Front axle force $(\mathrm{N})$ 20000

- Front brake force $(\mathrm{N})$ 1

- Braking time (sec)

- Energy for front brake rotor (J)

- Initial Velocity $(\mathrm{m} / \mathrm{s})$ 418000

- Braking Torque (Nm) 
From previous research [8], the optimum values of the exponents (A and $B$ ) in the objective function was achieved to be $(\mathrm{A}=1, \mathrm{~B}=1)$. The optimum diameter is kept almost constant irrespective of temperature exponent variation. Optimum rotor thickness decreases slightly with the decrease of the temperature exponent. The optimum diameter is almost constant with the reduction of the disc volume exponent. The optimum rotor thickness increases slightly as the rotor volume exponent decreases. The reduction in rotor thickness leads to a lower rotor volume. However, an increase in the temperature is obtained due to the decrease in the rotor thickness. This increase is close to the maximum temperature of the rotor material, and may have an effect on the wear of the pads. However the wear model used in the analysis doesn't take into account the change of the wear rate at higher temperature. A remarkable decrease in the rotor thermal stresses is achieved as a result of the optimum parameters, which has a great effect on the thermal life of the rotor, as well as, the life of the pads.

The optimization results for general cases produce optimum values of the design vector, as well as, optimum behavioral variables of crown brakes. A wide range of energy is covered for all possible applications of crown brakes. The results are obtained for different decelerations of automotive or other applications.

Figure (5) shows the effect of the braking energy on the optimum rotor diameter $\left(D_{R} *\right)$ for different decelerations. At low energy a smaller optimum diameter is obtained, which increases with the increase of the deceleration values.

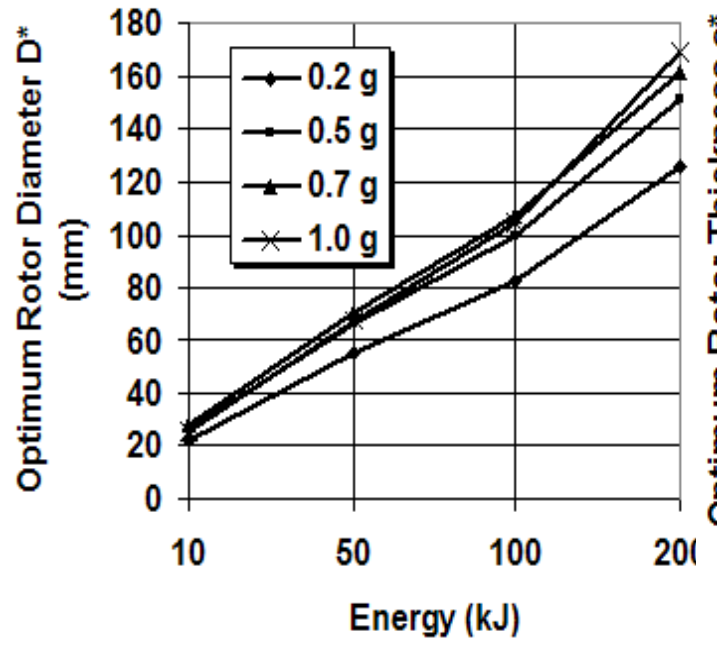

Figure 5: Effect of braking energy on the optimum outer rotor diameter for different decelerations.

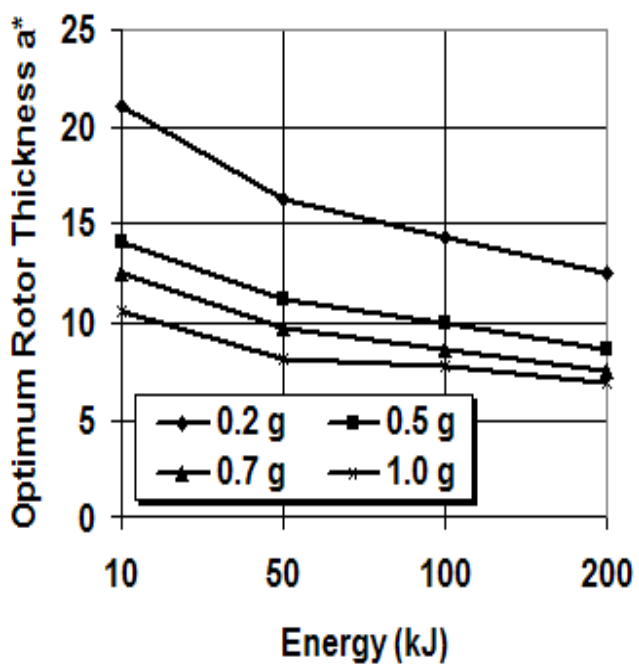

Figure 6: Effect of braking energy on the optimum rotor thickness for different decelerations. 

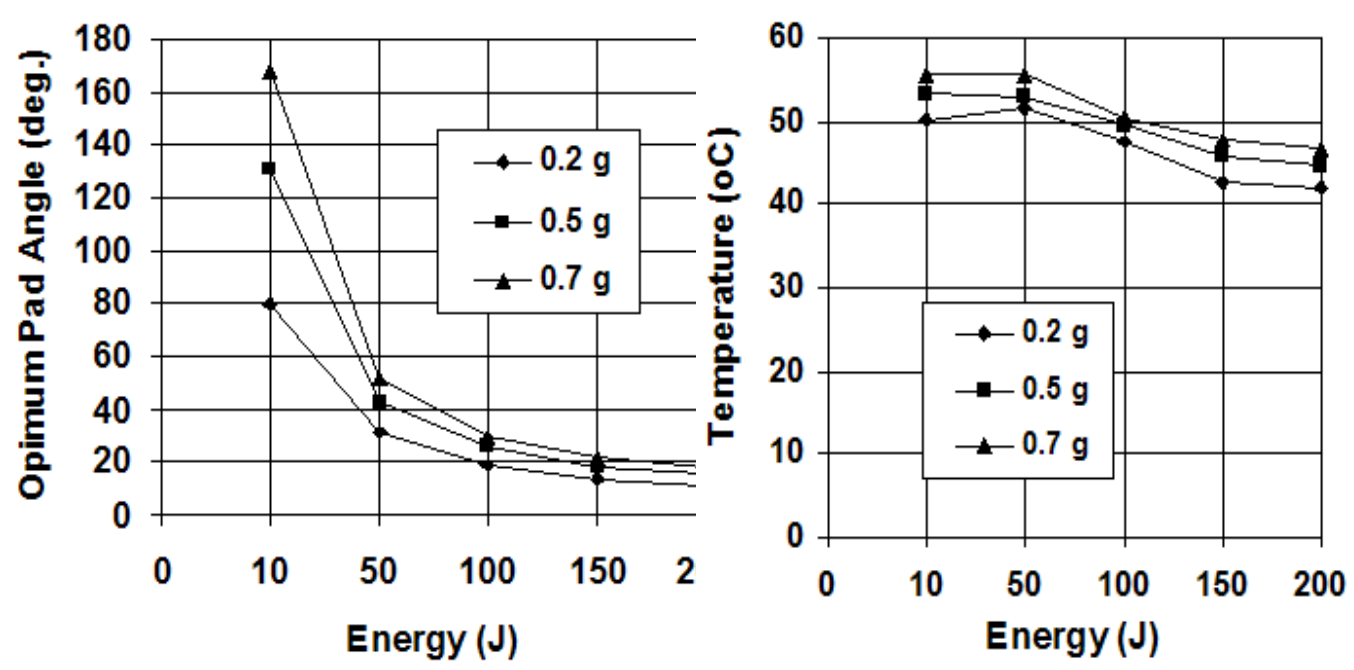

Figure 7: Effect of braking energy on the optimum pad angle for different decelerations.
Figure 8: Effect of braking energy on the optimum rotor temperature for different decelerations.

\section{Objective}

Function

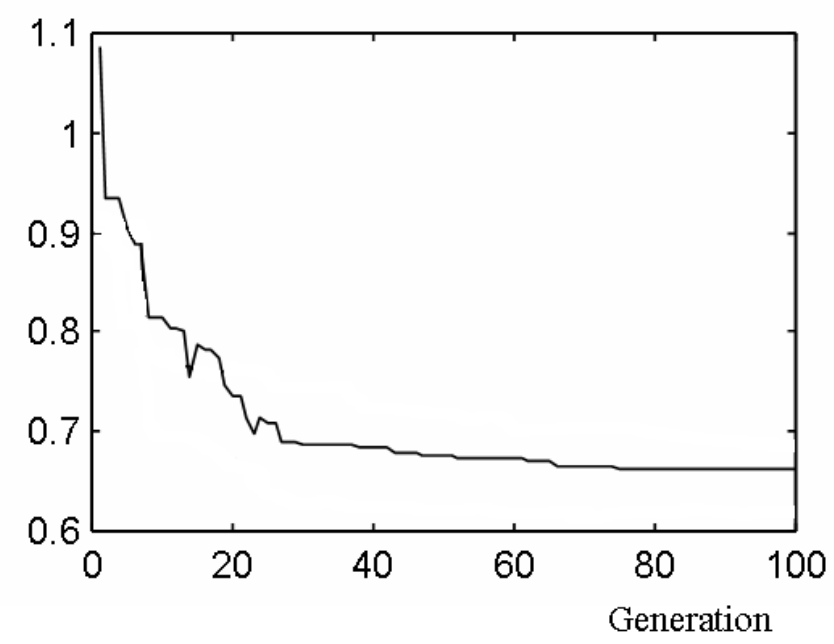

Figure 9: Convergence curve for GAs

The optimum rotor thickness $\left(\mathrm{a}_{\mathrm{R}}^{*}\right)$, for different decelerations is almost constant and independent of the energy as shown in Figure (6). The large optimum rotor thickness is obtained at the lower deceleration.

The optimum pad angle $\left(\alpha_{\mathrm{P}}^{*}\right)$ increases with the increase of the value of deceleration as shown in Figure (7). It is important to take into consideration that 
practically the pad angle $\left(\alpha_{\mathrm{P}}^{*}\right)$ should be lower than $90^{\circ}$. This is required in order to have enough space for the caliper, and also to have a good contact between the pad and the rotor.

A higher temperature is obtained when braking at higher deceleration. The temperature is almost constant with a slight decrease in temperature occurring with the increase of the energy as shown in Figure (8). The rate of convergence of the GAs run is shown in Figure (9). After 60 generations will not improve the value of the objective function, since it is almost constant after that. The increase in number of generations over 60 will not decrease the value of the objective function, but increases the computational time required for each run.

\section{CONCLUSION}

The present work introduced a procedure for computer-aided optimum design of crown brakes with optimized competing objectives. The design vector for optimizing crown brakes is composed of the outer rotor diameter, rotor width, rotor thickness, and pad angle. The main objective function is to minimize both rotor interface temperature rise and the rotor volume. A compound objective function with exponents is used.

Optimum design results and behavioral variables show that at low energy a smaller optimum rotor diameter is obtained, which increases with the increase of the deceleration values. Optimum rotor thickness is found to be almost constant and independent of the energy. An increase in the pad angle is obtained with the increase in the deceleration and the decrease of energy. A higher temperature is obtained when braking at higher deceleration. The temperature is almost constant with a slight decrease in temperature occurring with the increase of the energy. The numerical results were given in graphical to be used as design curves for crown brakes, for a wide range of energies and deceleration rates. The developed optimum design procedure in this paper can be applied to problems with larger number of design variables, and difficult objective functions.

\section{REFERENCES}

1- Day, A.J., Newcomb, T.P., "The Dissipation of Friction Energy from the Interface of an Annular Disc Brake", Proceeding of the Institution of Mechanical Engineers, Part D: Journal of Automobile Engineering, Vol. 198D, No.11, pp. 201-209, 1984.

2- Day, A.J., Tirovic, M., Newcomb, T.P., "Thermal Effects and Pressure Distribution in Brakes", Proceeding of the Institution of Mechanical Engineers, Part D: Journal of Automobile Engineering, Vol. 205, pp. 199-205, 1991.

3- Dike, G., "On Optimum Design of Disk Brakes", Transaction of the ASME, Journal of Engineering for Industry, pp. 863-869, 1974.

4- Elbella, A., Seireg, A., "Optimum Design of Crown Brakes", Proceeding of the ASME Design Automation Conference, Montreal, Canada, Sep 17-21, 1989.

5- Fermer, M., "Brake Discs for Passenger Trains-A Theoretical and Experimental Comparison of Temperatures and Stresses in Solid and Ventilated Discs", Proceeding of the Institution of Mechanical Engineers, Part F: Journal of Rail and Rapid Transit, Vol. 206, pp. 37-46, 1992. 
6- Goldberg, D.E., "Genetic Algorithms in Search, Optimization and Machine Learning", Addison-Wesley, Reading, MA, 1989.

7- Herrera, F., Lozano, M. and Verdegay, J.L., "Tackling Real-Coded Genetic Algorithms: Operators and Tools for Behavioural Analysis", Artificial Intelligence Review, Vol. 12, pp. 265-319, 1998.

8- Metwalli, S.M., Hegazi, H.A., "Computer-Based Design of Disc Brakes by MultiObjective Form Optimization", Proceeding of the ASME Design Engineering Technical Conference, Pittsburgh, Pennsylvania, Sept. 9-12, Paper No. DETC2001/CIE-21680, 2001.

9- Missori, S., Sili, A., "Optimizing Proportions of Railway Brake Discs by Temperature Transients Evaluation", of the Institution of Mechanical Engineers, Vol. 202, No D2, pp. 91-99, 1988.

10- Mouza, J. C., "Valeo Crown Brakes", SAE Paper No. 820027, 1982.

11- Nassef, A.O., Hegazi, H.A., and Metwalli, S.M., "Design of C-Frames Using RealCoded Genetic Optimization Algorithms and NURBS", ASME Design Engineering Technical Conference, Sept. 12-16, Las-Vegas, Nevada, Paper No. DETC 99/CIE9138, 1999.

12- Newcomp, T.P., "Thermal Aspects of Vehicle Braking: Heat Generated, Calculation of Temperature and of Braking Area Required and Correlation Between Theory and Practice", Journal of Automobile Engineer, July, pp. 288294, 1960.

13- Newcomp, T.P., "Thermal Aspects of Vehicle Braking: Part II: Temperature Attained Under Various Conditions of Vehicle Operation", Journal of Automobile Engineer, July, pp. 326-333, 1960.

14- Newcomp, T.P., "Interfacial Temperatures and the Distribution of Heat Between Bodies in Sliding Contact", Int. Heat Transfer Conf., ASME, 1961.

16- Newcomp, T.P., "Energy dissipation During Braking”, Wear, Vol. 59, pp. 401407, 1980.

17- Noyes, R.N., Vickers, P.T., "Prediction of Surface Temperatures in Passenger Car Disc Brakes", SAE Paper No. 690457, 1969.

18- Triovic, M., Day, A.J., "Disc Brake Interface Pressure Distributions", Proceeding of the Institution of Mechanical Engineers, Part D: Journal of Automobile Engineering, Vol. 205, pp. 137-146, 1991.

19- Yang, H., Xue, D., Tu, Y.L., "Modeling of Non-Linear Relations Among Different Design Evaluation Measures For Multi-Objective Design Optimization", Proceeding of ASME International Computers and Information in Engineering Conference, California, DETC2005-84425, 2005. 


\section{"التصميم الامثل للفرامل التاجية باستخدام الخواريزمات الجينية ذات التكويد الحقيقى"}

هذا البحث يقدم خطوات التصميم الامثل للفرامل التاجيـة ـ تختلف الفرامل التاجيـة عن الفرامل ذات الطنبورة من حيث ان السخونة الداخلة تكون من الناحيتين للقرص ـ ايضا تختلف عن الفرامل القرصية

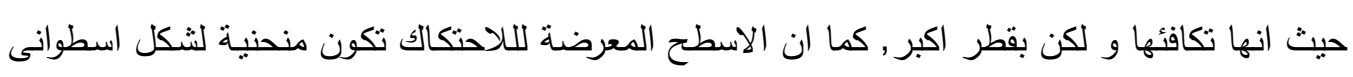

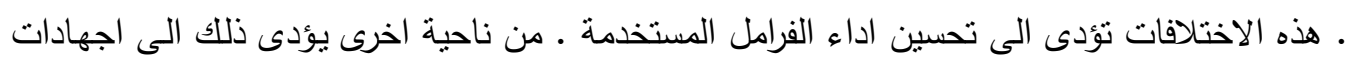

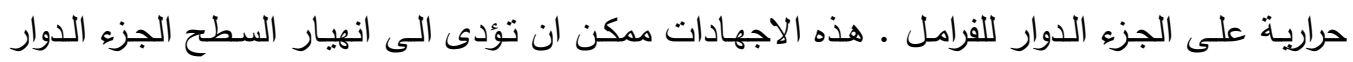

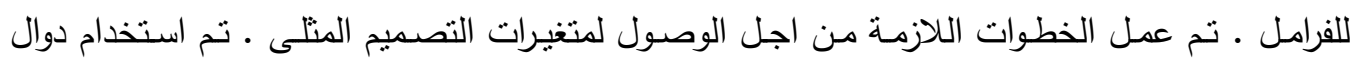

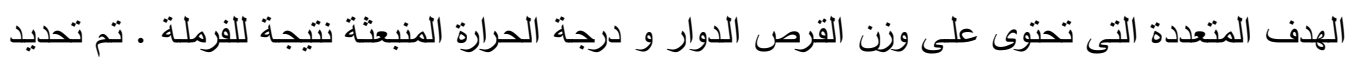

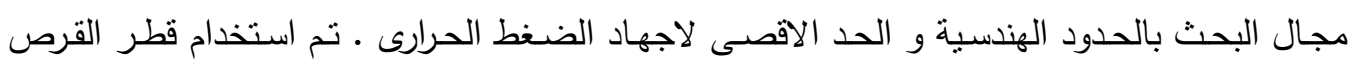

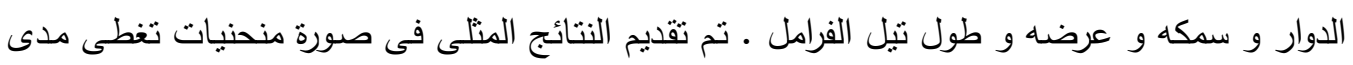
كبير من الطاقة و معدل تتاقص السرعة . 